\title{
Nonlinear Inelastic Earthquake Analysis of 2D Steel Frames
}

\author{
Phu-Cuong Nguyen \\ Department of Structural Engineering \\ Ho Chi Minh City Open University \\ Ho Chi Minh City, Vietnam \\ cuong.pn@ou.edu.vn
}

\begin{abstract}
In this work, a new method for nonlinear time-history earthquake analysis of 2D steel frames by a fiber plastic hinge method is presented. The beam-column element based on the displacement-based finite element method is established and formulated in detail using a fiber plastic hinge approach and stability functions. Geometric nonlinearities are taken into accounting by stability functions and the geometric stiffness matrix. A nonlinear dynamic algorithm is established based on the combination of the Newmark integration method and the Newton-Raphson iterative algorithm for solving dynamic equations. The proposed program predicts the nonlinear in elastic responses of 2D steel frames subjected to earthquakes as efficiently and accurately as commercial software. This study also shows that the initial residual stresses of steel should be considered in nonlinear inelastic time-history earthquake analysis of 2D steel frames while SAP2000 does not consider the effects of residual stresses.
\end{abstract}

Keywords-earthquake; inelasticity; geometric nonlinearity; stability functions; nonlinear algorithm; steel frames

\section{INTRODUCTION}

Nowadays, steel frames are widely used in civil engineering and pre-engineering buildings. There are two analysis methods for designing steel structures: first-order elastic analysis and direct analysis. In the first-order elastic analysis, structures are assumed to be still elastic, and the effects of nonlinearities are neglected, while in the direct analysis, all important nonlinear phenomena, such as the plasticity of materials, geometric nonlinearity, residual stresses, the flexibility of connections, etc., are considered. There are two common direct analysis methods: plastic hinge method [1-9] and distributed plasticity method [10-19]. Distributed plasticity method is complicated, computationally expensive, but more accurate. Plastic hinge method is simple, effective, and with acceptable accuracy. There are several studies on steel frames subjected to dynamic loadings using finite element method. In 1991, authors in [20] carried out 44 shaking table tests on steel frames with flexible, semi-rigid, and rigid connections. In 1994, authors in [21] studied the seismic behavior of two-story steel frames with semi-rigid connections. They concluded that the semi-rigid steel frame is suitable for earthquake-resistant design. Authors in [22] studied the dynamic behavior of steel frames with beam flanges shaved around the weld connection. They discovered that the dissipation capacity of the new design connection is much better than traditional connections. In 2008, authors in [23] analyzed the nonlinear elastic dynamic behavior of steel portal frames with semi-rigid connections. Authors in [24] developed a dynamic time-history analysis for steel frames using one element per member. Authors in [25] studied the nonlinear dynamic collapse analysis of semi-rigid steel frames using the finite particle method. Nguyen and Kim developed a plastic hinge method using stability functions for nonlinear dynamic analysis of steel frames [6, 7, 13], including the effects of semi-rigid connections and also developed distributed plasticity methods using stability functions for nonlinear dynamic analysis of semi-rigid steel frames employed by the Hilber-Hughes-Taylor method for solving dynamic equations [14, 15, 17]. Recently, authors in [26-28] tried to investigate the behavior of steel frames with the effects of connections. To the best of our knowledge, there is no study on the fiber plastic hinge method using stability functions for nonlinear dynamic analysis of steel frames.

In this paper, a fiber plastic hinge method for nonlinear inelastic time-history earthquake analysis of $2 \mathrm{D}$ steel frames was developped. Stability functions are used for optimizing the number of finite elements for structural analysis and simultaneously considering the second-order effects. The plastic hinges are divided into several fibers for capturing accurately gradual plasticity of hinges and so that the impact of residual stresses are directly considering as initial stresses. The Newmark integration method and the Newton-Raphson iterative algorithm are combined for solving dynamic equilibrium equations of structures. The proposed program can be developed for direct analysis and design of steel frames.

\section{NONLINEAR 2D BEAM-COLUMN}

\section{A. $\quad P-\delta$ Effect}

Stability functions studied in [29] were utilized for predicting the $P-\delta$ effect. The second-order effect can be captured precisely by stability functions. With one element for the member, it is efficient to economize sources and analysis time. Residual stresses are assigned as the initial stress pattern of ECCS [30]. The force-displacement relationship using the incremental form of a $2 \mathrm{D}$ beam-column element can be written as: 


$$
\left\{\begin{array}{c}
\Delta P \\
\Delta M_{I} \\
\Delta M_{J}
\end{array}\right\}=\frac{E I}{L}\left[\begin{array}{ccc}
A / I & 0 & 0 \\
0 & S_{1} & S_{2} \\
0 & S_{2} & S_{1}
\end{array}\right]\left\{\begin{array}{c}
\Delta \delta \\
\Delta \theta_{I} \\
\Delta \theta_{J}
\end{array}\right\}
$$

where $\Delta P, \Delta M_{I}$, and $\Delta M_{J}$ are the axial force and moments, $\Delta \delta, \Delta \theta_{I}$, and $\Delta \theta_{J}$ are the axial movement and rotations, $A$ is the sectional area, $I$ is the moment of inertia around the $\mathrm{z}$ axis, $L$ is the elemental length, $E$ is Young's modulus of steel, and $S_{1}$ and $S_{2}$ are stability functions [29].

\section{B. Fiber Plastic Hinge}

In Figure 1 of [9] the fiber plastic hinge method is illustrated. In this method, two ends $I$ and $J$ of the element have monitored the behavior of stress and strain of fibers. If the fiber is yielding, the tangent elastic modulus of the fiber is assigned to be equal to zero. The force-displacement relation of a $2 \mathrm{D}$ element considering both the $P-\delta$ effect and plasticity can be formulated as:

$$
\left\{\begin{array}{c}
\Delta P \\
\Delta M_{I} \\
\Delta M_{J}
\end{array}\right\}=\frac{E_{t} I}{L}\left[\begin{array}{ccc}
A / I & 0 & 0 \\
0 & \eta_{I}\left(S_{1}-\frac{S_{2}^{2}}{S_{1}}\left(1-\eta_{J}\right)\right) & \eta_{I} \eta_{J} S_{2} \\
0 & \eta_{I} \eta_{J} S_{2} & \eta_{J}\left(S_{1}-\frac{S_{2}^{2}}{S_{1}}\left(1-\eta_{I}\right)\right)
\end{array}\right]\left\{\begin{array}{c}
\Delta \delta \\
\Delta \theta_{I} \\
\Delta \theta_{J}
\end{array}\right\}
$$

where $\eta_{I}$ is a scalar parameter accounting for the gradual yielding of the fiber hinge at the $I$ end, $\eta_{J}$ is a scalar parameter accounting for the gradual yielding of the fiber hinge at the $J$ end. They are estimated as:

$$
\begin{array}{r}
\eta_{I}=\frac{\sum_{i=1}^{n} E_{t I i}\left(A_{i} y_{i}^{2}+I_{i}\right)}{E_{t} I} \\
\eta_{J}=\frac{\sum_{i=1}^{n} E_{t J i}\left(A_{i} y_{i}^{2}+I_{i}\right)}{E_{t} I}
\end{array}
$$

where $n$ is the sum of fibers on the sections at $I$ and $J, E_{t I i}$ and $E_{t J i}$ are the tangent moduli of the $i^{t h}$ fiber at $I$ and $J, A_{i}$ is the area of the $i^{\text {th }}$ fiber, $I_{i}$ is the moment of inertia of the $i^{\text {th }}$ fiber, $y_{i}$ is the center coordinate of the $i^{\text {th }}$ fiber, and $E_{t}$ is the tangent modulus of an element.

\section{Shear Deformation}

For calculating the effects of shear deformation, the incremental equilibrium equation is modified for $2 \mathrm{D}$ beamcolumn element as:

$$
\left\{\begin{array}{c}
\Delta P \\
\Delta M_{I} \\
\Delta M_{J}
\end{array}\right\}=\left[\begin{array}{ccc}
E_{t} A / L & 0 & 0 \\
0 & D_{i i} & D_{i j} \\
0 & D_{i j} & D_{j j}
\end{array}\right]\left\{\begin{array}{c}
\Delta \delta \\
\Delta \theta_{I} \\
\Delta \theta_{J}
\end{array}\right\}
$$

where:

$$
\begin{gathered}
D_{i i}=\frac{K_{i i} K_{i j}-K_{i j}^{2}+K_{i i} A_{s} G L}{K_{i i}+K_{j j}+2 K_{i j}+A_{s} G L} \\
D_{i j}=\frac{-K_{i i} K_{j j}+K_{i j}^{2}+K_{i j} A_{s} G L}{K_{i i}+K_{j j}+2 K_{i j}+A_{s} G L} \\
D_{j j}=\frac{K_{i i} K_{j j}-K_{i j}^{2}+K_{j j} A_{s} G L}{K_{i i}+K_{j j}+2 K_{i j}+A_{s} G L}
\end{gathered}
$$

\section{D. $P-\Delta$ Effect}

Figure 1 presents a 2D element with six degrees of freedom. The elemental tangent stiffness matrix considering the $P-\Delta$ effect is calculated as:

$$
[K]_{T}=[T]_{3 \times 5}^{T}\left[K_{e}\right]_{3 \times 3}[T]_{3 \times 5}+\left[K_{g}\right]_{5 \times 5}
$$

where the transformation matrix $[T]_{3 \times 5}$ of the element is formulated as:

$$
[T]_{3 \times 5}=\left[\begin{array}{ccccc}
-1 & 0 & 0 & 0 & 0 \\
0 & 1 & 0 & 1 / L & -1 / L \\
0 & 0 & 1 & 1 / L & -1 / L
\end{array}\right]
$$

and $\left[K_{g}\right]$ is the geometric stiffness matrix written as:

$$
\left[K_{g}\right]_{5 \times 5}=\left[\begin{array}{ccccc}
0 & 0 & 0 & \frac{M_{I}+M_{J}}{L^{2}} & -\frac{M_{I}+M_{J}}{L^{2}} \\
0 & 0 & 0 & 0 & 0 \\
0 & 0 & 0 & 0 & 0 \\
\frac{M_{I}+M_{J}}{L^{2}} & 0 & 0 & \frac{P}{L} & -\frac{P}{L} \\
-\frac{M_{I}+M_{J}}{L^{2}} & 0 & 0 & -\frac{P}{L} & \frac{P}{L}
\end{array}\right]
$$

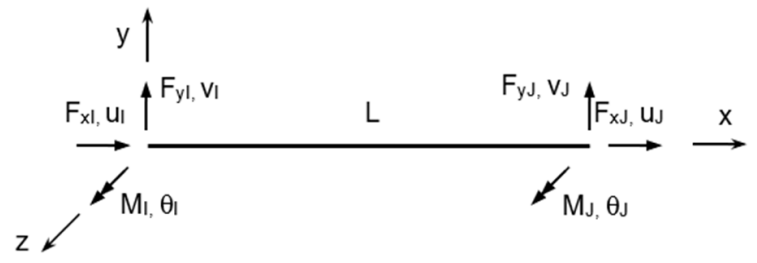

Fig. 1. Fiber plastic hinge method.

\section{NONLINEAR SOLUTION}

The nonlinear solution algorithm invented in [31] is developed to find a solution to the structural system. The balanced iteration at each time step is adjusted by the NewtonRaphson iterative method. The dynamic equilibrium equation of steel frames is written as:

$$
[M]\{\Delta \ddot{D}\}+[C]\{\Delta \dot{D}\}+\left[K_{T}\right]\{\Delta D\}=\{\Delta F\}
$$


where $[\Delta \ddot{D}]$ is the vector of incremental acceleration, $[\Delta \dot{D}]$ is the vector of incremental velocity, $[\Delta D]$ is the vector of incremental displacement, $[M]$ is the structural mass matrix, $[C]$ is the structural damping matrix, $\left[K_{T}\right]$ is the structural tangent stiffness matrix, and $\{\Delta F\}$ is the applied dynamic loading.

The structural damping matrix $[C]$ is calculated as the Rayleigh damping matrix [32]:

$$
[C]=\alpha_{M}[M]+\beta_{K}\left[K_{i}\right]
$$

where $\alpha_{M}$ is the mass-proportional damping factor, $\beta_{K}$ is the stiffness-proportional damping factor, and $\left[K_{i}\right]$ is the structural initial stiffness matrix.

If both first vibration modes of the structure are assumed to have the same damping ratio $\xi$, then:

$$
\alpha_{M}=\xi \frac{2 \omega_{1} \omega_{2}}{\omega_{1}+\omega_{2}} \quad ; \quad \beta_{K}=\xi \frac{2}{\omega_{1}+\omega_{2}}
$$

where $\omega_{1}$ is the natural frequency of the first vibration mode and $\omega_{2}$ is the natural frequency of the second vibration mode.

\section{VERIFICATION AND DISCUSSION}

In 1985, Vogel [33] proposed a portal steel frame subjected to static loadings for verifying the accuracy of the nonlinear inelastic analysis of finite element programs. In this paper, the Vogel steel frame subjected to earthquakes is studied as shown in Figure 2. Young's modulus is E=205,000MPa, Poisson's ratio is $v=0.30$, and the yield stress of steel is $\sigma_{y}=235 \mathrm{~Pa}$. The columns are out-of-straightness of $\psi=1 / 400$ for considering initial imperfection. The lumped masses of $50 \mathrm{kN} . \mathrm{s}^{2} / \mathrm{m}$ are put at the top of the columns. The frame was subjected to Loma Prieta and Northridge earthquakes (the data were taken from [34] and can be seen in Figure 3 and Table I). The fiber plastic hinges are divided into 429 fibers, 6×33=198 fibers for each flange, and $33 \times 1=33$ fibers for the web. The obtained results by the proposed program are compared with those of commercial software SAP2000 version 22 using the plastic hinge modeling of interaction P-M2-M3.

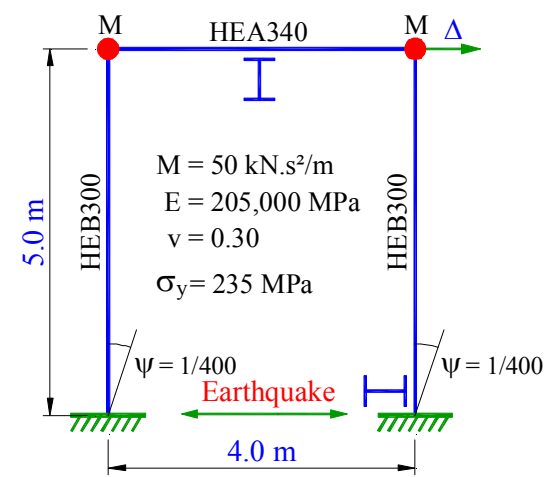

Fig. 2. Vogel steel frame subjected to earthquakes.
TABLE I. TIME STEPS AND GROUND ACCELERATION PEAK OF EARTHQUAKES

\begin{tabular}{|c|c|c|}
\hline Earthquake & Time step (s) & PGA (g) \\
\hline Loma Prieta (1989) & 0.005 & -0.529 \\
\hline Northridge (1994) & 0.010 & -0.640 \\
\hline
\end{tabular}

(a)

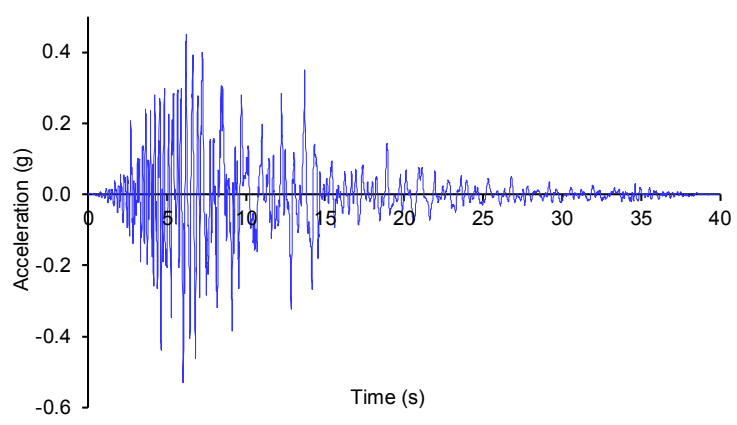

(b)

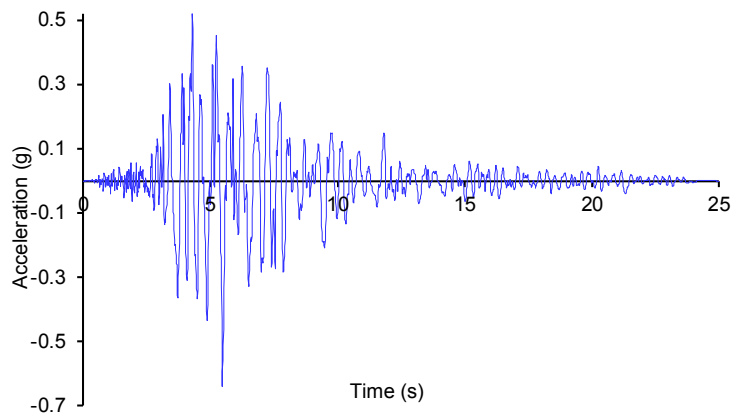

Fig. 3. Time-history of earthquakes: (a) Loma Prieta, (b) Northridge.

(a)

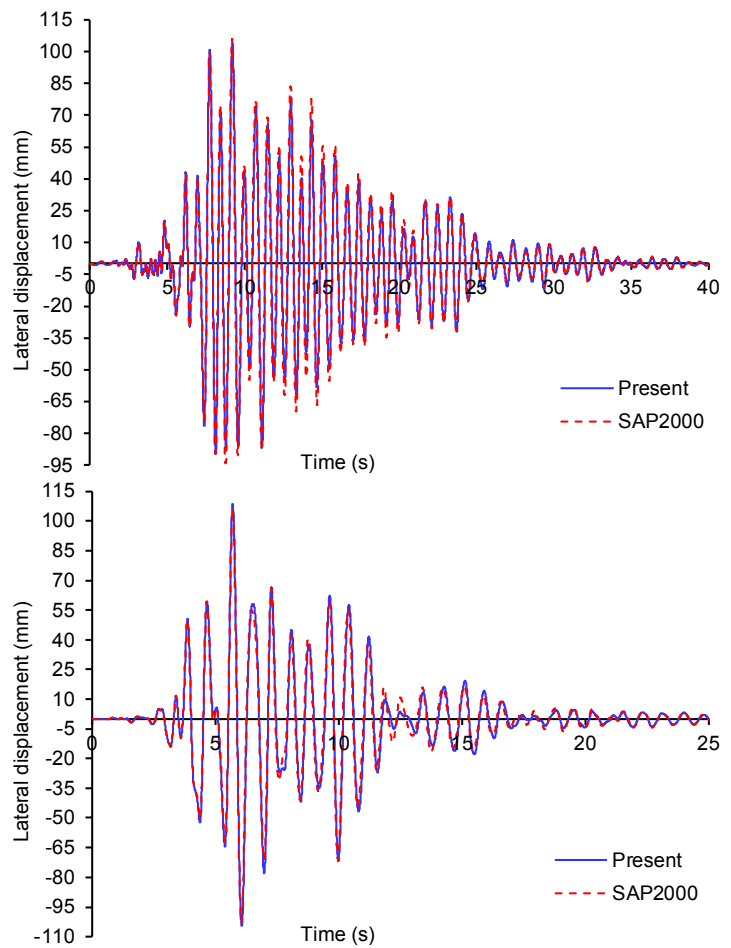

Fig. 4. Nonlinear elastic time-displacement responses of column top: (a) Loma Prieta, (b) Northridge 
Figures 4 and 5 show the time-lateral displacement response at the right-column top of the frame subjected to Loma Prieta and Northridge earthquakes performed by nonlinear elastic and inelastic dynamic analyses. It can be seen that the obtained results by the proposed program are in good agreement with those of SAP2000.

(a)

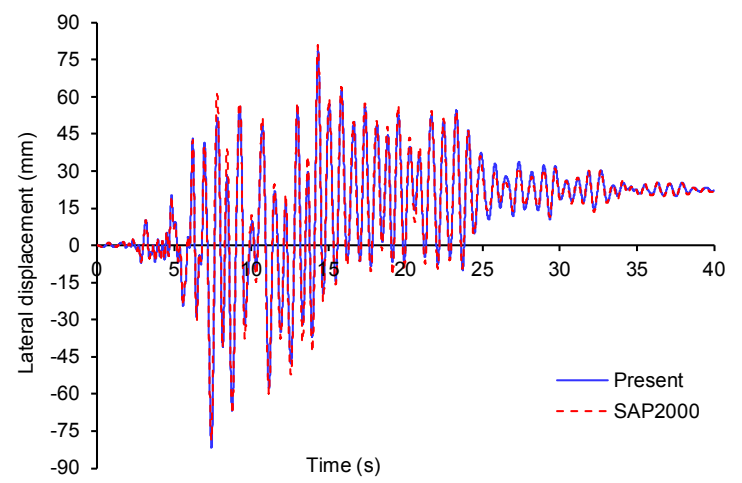

(b)

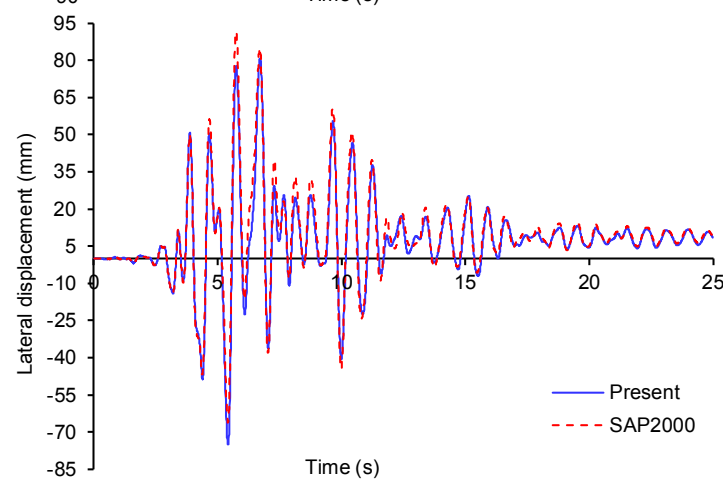

Fig. 5. Nonlinear inelastic time-displacement responses of column top: (a) Loma Prieta, (b) Northridge.

Figures 6 and 7 show the time-rotational displacement response at the right-column top of the frame subjected to Loma Prieta and Northridge earthquakes performed by nonlinear elastic and inelastic dynamic analyses. The obtained results by the proposed program are again in good agreement with those of SAP2000. However, under the Loma Prieta earthquake in the nonlinear inelastic analysis, the timerotational displacement responses of the proposed program and SAP2000 are different because the proposed program uses the proposed fiber plastic hinge method while SAP2000 uses the plastic hinge method. We can see that the proposed method is accurate and effective in predicting the nonlinear behavior of 2D steel frames subjected to earthquakes.

Commercial software SAP2000 does not consider the effects of residual stresses on the behavior and strength of steel frames. Figures 8 and 9 show the nonlinear inelastic timedisplacement response of the column top of the frame considering the effects of residual stresses (Present RS, red line) and without considering the effects of residual stresses (Present, blue line). It can be seen that the lateral displacement responses of the frame are almost the same (Figure 8), while the rotational displacement responses of the structure are clearly different if we consider the effects of residual stresses, as shown in Figure 9. Residual stresses may significantly impact the nonlinear inelastic behavior and strength of steel frames so they should be considered in engineering design.

(a)

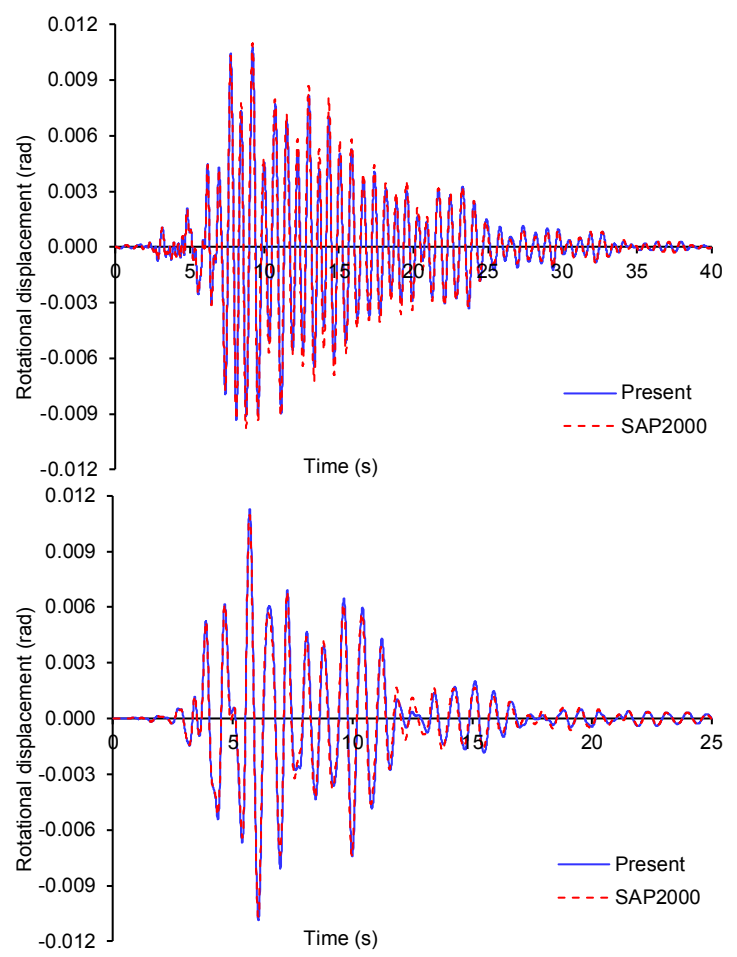

Fig. 6. Nonlinear elastic time-rotational displacement responses of column top: (a) Loma Prieta, (b) Northridge.

(a)

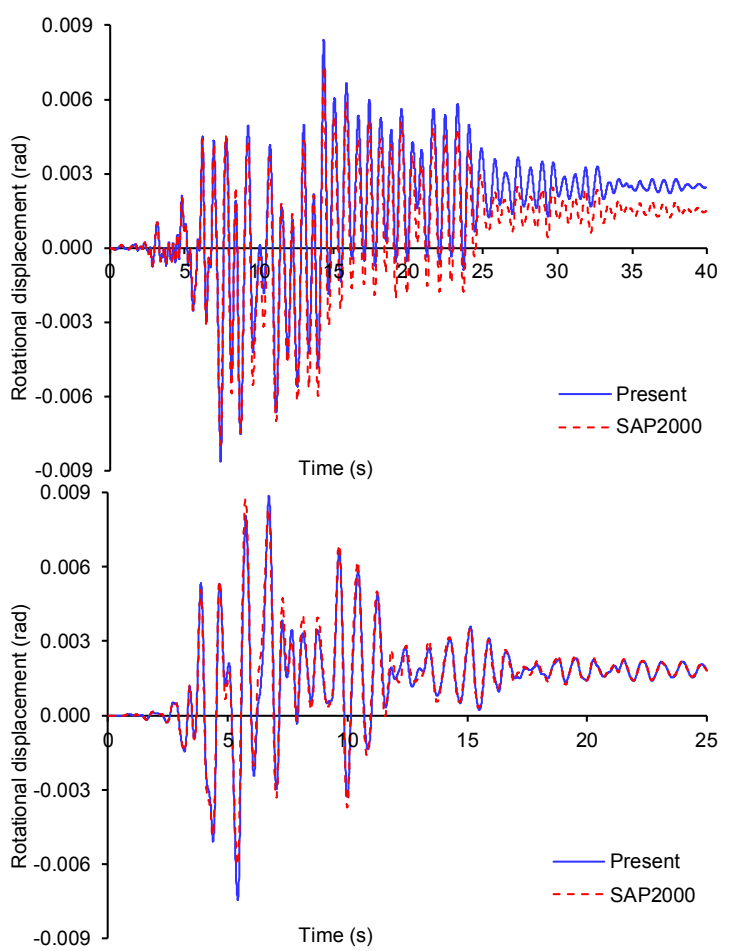

Fig. 7. Nonlinear inelastic time-rotational displacement responses of column top: (a) Loma Prieta, (b) Northridge. 
(a)

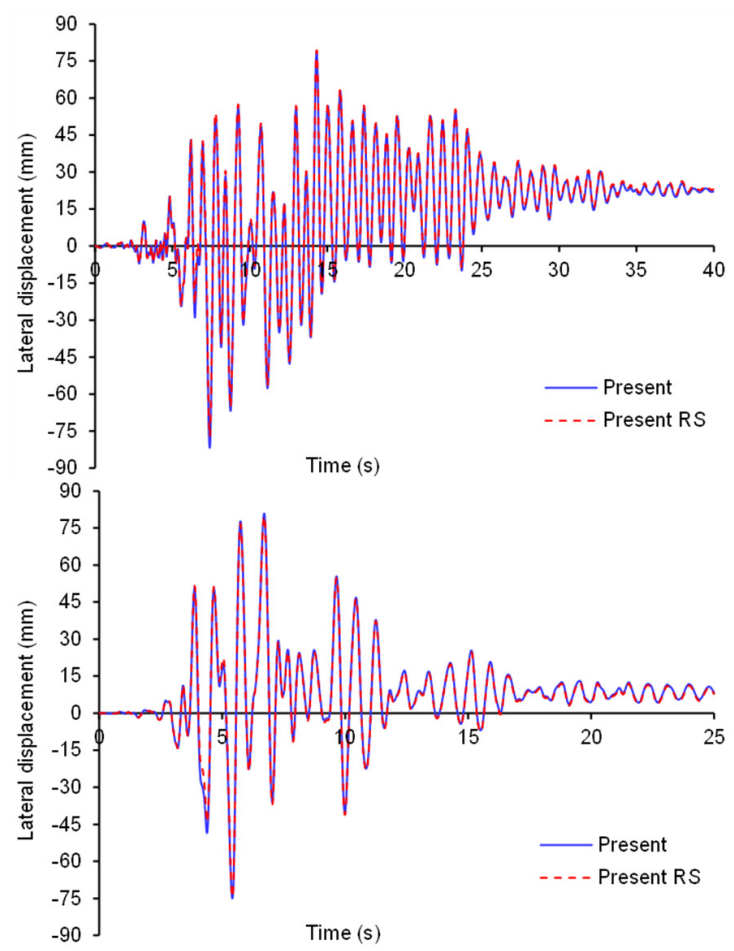

Fig. 8. The effects of residual stresses on nonlinear inelastic timedisplacement responses of column top: (a) Loma Prieta, (b) Northridge.

(a)

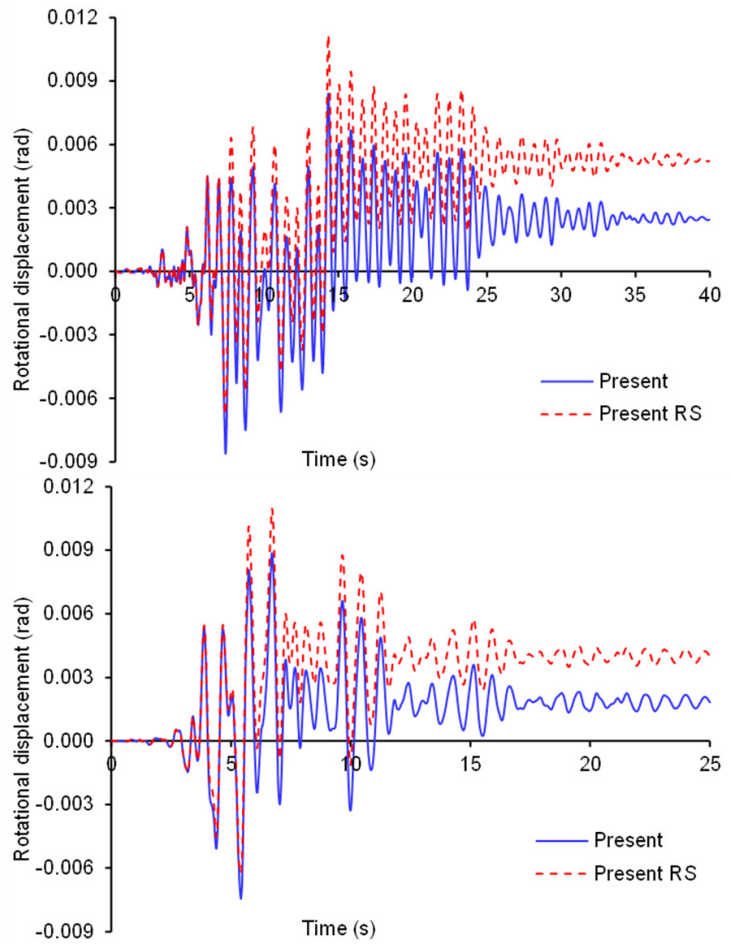

Fig. 9. The effects of residual stresses on nonlinear inelastic timerotational displacement responses of column top: (a) Loma Prieta, (b) Northridge.

\section{CONCLUSION}

A second-order inelastic analysis program based on the finite element method for $2 \mathrm{D}$ steel frames was developed successfully. The effects of $\mathrm{P}-\delta, \mathrm{P}-\Delta$, material inelasticity, residual stresses, and imperfections were accounted for the nonlinear analysis by the generalized displacement method. The proposed method is simple, accurate, and efficient in predicting the strength and behavior of steel frames. The proposed method can directly consider the effects of residual stresses of steel as SAP2000 cannot. The proposed method can be integrated into commercial software for daily engineering design using advanced analysis.

\section{ACKNOWLEDGMENT}

The authors gratefully acknowledge the financial support granted by the Scientific Research Fund of the Ministry of Education and Training (MOET), Vietnam. (No. B2019-MBS01). The authors would also like to thank Ho Chi Minh City Open University and colleagues for supporting this project.

\section{REFERENCES}

[1] W. S. King, D. W. White, and W. F. Chen, "Second-Order Inelastic Analysis Methods for Steel-Frame Design," Journal of Structural Engineering, vol. 118, no. 2, pp. 408-428, Feb. 1992, https://doi.org/10.1061/(ASCE)0733-9445(1992)118:2(408).

[2] S. L. Chan and P. T. Chui, Eds., Non-Linear Static and Cyclic Analysis of Steel Frames with Semi-Rigid Connections, 1st ed. Amsterdam, Netherlands: Elsevier Science, 2000.

[3] R. D. Ziemian and W. McGuire, "Modified Tangent Modulus Approach, A Contribution to Plastic Hinge Analysis," Journal of Structural Engineering, vol. 128, no. 10, pp. 1301-1307, Oct. 2002, https://doi.org/ 10.1061/(ASCE)0733-9445(2002)128:10(1301).

[4] Z.-H. Zhou and S.-L. Chan, "Elastoplastic and Large Deflection Analysis of Steel Frames by One Element per Member. I: One Hinge along Member," Journal of Structural Engineering, vol. 130, no. 4, pp. 538-544, Apr. 2004, https://doi.org/10.1061/(ASCE)0733-9445(2004) 130:4(538).

[5] C. Ngo-Huu, P.-C. Nguyen, and S.-E. Kim, "Second-order plastic-hinge analysis of space semi-rigid steel frames," Thin-Walled Structures, vol. 60, pp. 98-104, Nov. 2012, https://doi.org/10.1016/j.tws.2012.06.019.

[6] P.-C. Nguyen and S.-E. Kim, "Nonlinear inelastic time-history analysis of three-dimensional semi-rigid steel frames," Journal of Constructional Steel Research, vol. 101, pp. 192-206, Oct. 2014, https://doi.org/ 10.1016/j.jcsr.2014.05.009.

[7] P.-C. Nguyen and S.-E. Kim, "Investigating effects of various base restraints on the nonlinear inelastic static and seismic responses of steel frames," International Journal of Non-Linear Mechanics, vol. 89, pp. 151-167, Mar. 2017, https://doi.org/10.1016/j.ijnonlinmec.2016.12.011.

[8] P.-C. Nguyen and S.-E. Kim, "A new improved fiber plastic hinge method accounting for lateral-torsional buckling of 3D steel frames," Thin-Walled Structures, vol. 127, pp. 666-675, Jun. 2018, https://doi.org/10.1016/j.tws.2017.12.031.

[9] P. C. Nguyen, B. Le-Van, and S. D. T. V. Thanh, "Nonlinear Inelastic Analysis of 2D Steel Frames :," Engineering, Technology \& Applied Science Research, vol. 10, no. 4, pp. 5974-5978, Aug. 2020, https://doi.org/10.48084/etasr.3600.

[10] C. M. Foley and S. Vinnakota, "Inelastic analysis of partially restrained unbraced steel frames," Engineering Structures, vol. 19, no. 11, pp. 891902, Nov. 1997, https://doi.org/10.1016/S0141-0296(97)00175-2.

[11] L. H. Teh and M. J. Clarke, "Plastic-Zone Analysis of 3D Steel Frames Using Beam Elements," Journal of Structural Engineering, vol. 125, no. 11, pp. 1328-1337, Nov. 1999, https://doi.org/10.1061/(ASCE)07339445(1999)125:11(1328). 
[12] X.-M. Jiang, H. Chen, and J. Y. R. Liew, "Spread-of-plasticity analysis of three-dimensional steel frames," Journal of Constructional Steel Research, vol. 58, no. 2, pp. 193-212, Feb. 2002, https://doi.org/ 10.1016/S0143-974X(01)00041-4.

[13] P.-C. Nguyen and S.-E. Kim, "Nonlinear elastic dynamic analysis of space steel frames with semi-rigid connections," Journal of Constructional Steel Research, vol. 84, pp. 72-81, May 2013, https://doi.org/10.1016/j.jcsr.2013.02.004.

[14] P.-C. Nguyen, N. T. N. Doan, C. Ngo-Huu, and S.-E. Kim, "Nonlinear inelastic response history analysis of steel frame structures using plasticzone method," Thin-Walled Structures, vol. 85, pp. 220-233, Dec. 2014, https://doi.org/10.1016/j.tws.2014.09.002.

[15] P.-C. Nguyen and S.-E. Kim, "Distributed plasticity approach for timehistory analysis of steel frames including nonlinear connections," Journal of Constructional Steel Research, vol. 100, pp. 36-49, Sep. 2014, https://doi.org/10.1016/j.jcsr.2014.04.012.

[16] P.-C. Nguyen and S.-E. Kim, "An advanced analysis method for threedimensional steel frames with semi-rigid connections," Finite Elements in Analysis and Design, vol. 80, pp. 23-32, Mar. 2014, https://doi.org/10.1016/j.finel.2013.11.004.

[17] P.-C. Nguyen and S.-E. Kim, "Second-order spread-of-plasticity approach for nonlinear time-history analysis of space semi-rigid steel frames," Finite Elements in Analysis and Design, vol. 105, pp. 1-15, Nov. 2015, https://doi.org/10.1016/j.finel.2015.06.006.

[18] A. Saritas and A. Koseoglu, "Distributed inelasticity planar frame element with localized semi-rigid connections for nonlinear analysis of steel structures," International Journal of Mechanical Sciences, vol. 9697, pp. 216-231, Jun. 2015, https://doi.org/10.1016/j.ijmecsci.2015. 04.005 .

[19] P.-C. Nguyen and S.-E. Kim, “Advanced analysis for planar steel frames with semi-rigid connections using plastic-zone method," Steel and Composite Structures, vol. 21, no. 5, pp. 1121-1144, Jan. 2016.

[20] M. N. Nader and A. Astaneh, "Dynamic behavior of flexible, semirigid and rigid steel frames," Journal of Constructional Steel Research, vol. 18, no. 3, pp. 179-192, Jan. 1991, https://doi.org/10.1016/0143974X(91)90024-U.

[21] A. S. Elnashai and A. Y. Elghazouli, "Seismic behaviour of semi-rigid steel frames," Journal of Constructional Steel Research, vol. 29, no. 1, pp. 149-174, Jan. 1994, https://doi.org/10.1016/0143-974X(94)90060-4.

[22] S.-J. Chen, J. M. Chu, and Z. L. Chou, "Dynamic behavior of steel frames with beam flanges shaved around connection," Journal of Constructional Steel Research, vol. 42, no. 1, pp. 49-70, Apr. 1997, https://doi.org/10.1016/S0143-974X(97)00011-4.

[23] J. G. S. da Silva, L. R. O. de Lima, P. C. G. da S. Vellasco, S. A. L. de Andrade, and R. A. de Castro, "Nonlinear dynamic analysis of steel portal frames with semi-rigid connections," Engineering Structures, vol. 30, no. 9, pp. 2566-2579, Sep. 2008, https://doi.org/10.1016/j.engstruct. 2008.02.011.

[24] S.-W. Liu, R. Bai, and S.-L. Chan, "Dynamic Time-history Elastic Analysis of Steel Frames Using One Element per Member," Structures, vol. 8, pp. 300-309, Nov. 2016, https://doi.org/10.1016/ j.istruc.2016.05.006.

[25] Y. Yu and X. Zhu, "Nonlinear dynamic collapse analysis of semi-rigid steel frames based on the finite particle method," Engineering Structures, vol. 118, pp. 383-393, Jul. 2016, https://doi.org/10.1016/ j.engstruct.2016.03.063.

[26] N. L. Tran and T. H. Nguyen, "Reliability Assessment of Steel Plane Frame's Buckling Strength Considering Semi-rigid Connections," Engineering, Technology \& Applied Science Research, vol. 10, no. 1, pp. 5099-5103, Feb. 2020, https://doi.org/10.48084/etasr.3231.

[27] N. W. Bishay-Girges, "Improved Steel Beam-Column Connections in Industrial Structures," Engineering, Technology \& Applied Science Research, vol. 10, no. 1, pp. 5126-5131, Feb. 2020, https://doi.org/ 10.48084/etasr.3248.

[28] N. Konkong, "An Investigation on the Ultimate Strength of ColdFormed Steel Bolted Connections," Engineering, Technology \& Applied Science Research, vol. 7, no. 4, pp. 1826-1832, Aug. 2017, https://doi.org/10.48084/etasr.1243.
[29] W.-F. Chen, Structural Stability: Theory and Implementation, 1st Edition. Englewood Cliffs, N.J.: Prentice Hall, 1987.

[30] European Convention for Constructional Steelwork, S. S. Technical Committee 8, European Convention for Constructional Steelwork, Technical Working Group 8.2, and System, Ultimate limit State calculation of sway frames with rigid joints. Rotterdam, Netherlands: ECCS, 1984.

[31] N. M. Newmark, "A Method of Computation for Structural Dynamics," Journal of the Engineering Mechanics Division, vol. 85, no. 3, pp. 6794, 1959.

[32] G. Augusti, "Dynamics of structures: Theory and applications to earthquake engineering," Meccanica, vol. 31, no. 6, pp. 719-720, Dec. 1996, https://doi.org/10.1007/BF00426980.

[33] U. Vogel, “Calibrating frames,” Stahlbau, vol. 54, pp. 295-301, 1985.

[34] "PEER Ground Motion Database - PEER Center." https://ngawest2. berkeley.edu/ (accessed Oct. 15, 2020). 